\title{
Effects of Lisinopril on Experimental Ischemia in Rats. Influence of Infarct Size
}

\author{
Leonardo A. M. Zornoff, Beatriz B. Matsubara, Luiz S. Matsubara, Sérgio A. R. Paiva, \\ Maria T. T. Tornero, Joel Spadaro \\ Botucatu, SP - Brazil
}

Objective - Angiotensin-converting enzyme inhibitors (ACEIs) have gained importance in preventing or attenuating the process of ventricular remodeling after myocardial infarction. The significance of infarct size in regard to the response to ACEIs, however, is controversial. This study aimed to analyze the effects of lisinopril on mortality rate, cardiac function, degree of cardiac hypertrophy and fibrosis in rats with different infarct sizes.

Methods - Lisinopril (20 $\mathrm{mg} / \mathrm{kg} /$ day) dissolved in drinking water was administered to rats immediately after coronary artery occlusion. After being sacrificed, the infarcted animals were divided into two groups: one group of animals with small infarcts ( $<40 \%$ of the left ventricle) and another group of animals with large infarcts $(>40 \%$ of the left ventricle).

Results - The mortality rate was $31.7 \%$ in treated rats and $47 \%$ in the untreated rats. There was no statistical difference between the groups with small and large infarcts in regard to myocardial concentration of hydroxyproline. In small infarcts, the treatment attenuated the heart dysfunction characterized by lower levels of blood pressure and lower values of the first derivative of pressure and of the negative derivative of pressure. The degree of hypertrophy was also attenuated in small infarcts. In regard to large infarcts, no differences between the groups were observed.

Conclusion - Treatment with the ACEIs had no effect on mortality rate and on the amount of fibrosis. The protective effect of lisinopril on heart function and on the degree of hypertrophy could only be detected in small infarcts

Keywords: myocardial infarction, rat, lisinopril

Faculdade de Medicina de Botucatu - UNESP

Mailing address: Leonardo A. M. Zornoff - Faculdade de Medicina de Botucatu UNESP - Depto de Clínica Médica - Rubião Jr, S/N - 18618-000 - Botucatu, SP, Brazil

Received on 3/3/99

Acepted on 6/7/99
Changes in ventricular architecture involving the infarcted and the noninfarcted regions often occur following an acute myocardial infarction. In recent years, these adaptations have been studied under the name of post-acute myocardial infarction ventricular remodeling ${ }^{1}$.

In the initial phase of the acute myocardial infarction, acute ventricular dilation may be observed, characterized by reduction in thickness and distension of the infarcted region. This change is called expansion of the infarct and results from the sliding of necrotic muscle areas due to disintegration of the interfibrillar collagen. In the late phase, different degrees of heart dilation are sequentially observed, depending on the intensity of the ventricular manifestation that occurred in the initial period. The late cavitary dilation results from the hypertrophic process, which involves both ventricles and seems to be an adaptation to the new load situations ${ }^{1}$.

Acknowledgment and understanding of this process is crucial because ventricular remodeling is associated with a worse postinfarction prognosis. This happens because the presence and intensity of ventricular remodeling are related to a higher incidence of aneurysm formation, cardiac rupture, functional worsening, arrhythmias, and a higher mortality rate ${ }^{2}$.

Another significant feature of ventricular remodeling is that its evolution can be altered through several therapeutical interventions. In recent years, the use of angiotensin-converting enzyme inhibitors (ACEIs) has gained importance as a strategy for attenuating this process. Some doubts persist, such as in which situations would hearts undergoing infarction benefit from this treatment?

Therefore, the objective of this study was to analyze the effects of the administration of ACEIs on possible noxious effects of ventricular remodeling in different infarct sizes.

\section{Methods}

We analyzed 293 male Wistar rats from the vivarium of the Botucatu campus of the Universidade do Estado de São Paulo (UNESP). Their weights ranged from $200 \mathrm{~g}$ to $250 \mathrm{~g}$.

Acute myocardial infarction was produced according 
to a previously described method ${ }^{3}$ that had already been standardized in our laboratory ${ }^{4}$. Briefly, after anesthesia through ether inhalation, a left thoracotomy was performed between the $4^{\text {th }}$ and the $5^{\text {th }}$ intercostal spaces. The heart was then exteriorized through lateral compression of the thorax and the left coronary artery was ligated, $2 \mathrm{~mm}$ from its origin, with a polyvinyl thread (5-0, Ethicon) between the margin of the left atrium and the sulcus of the pulmonary artery. Then, the heart was rapidly returned to the thoracic cavity, the thorax was closed, and the animals were put in cages to recover. They were fed a commercial food preparation and had free access to water. After 12 hours, which corresponds to the period stipulated by us as necessary for surgical recovery, 3 groups of animals were established as follows: 1 . group NT ( $n=51)$ consisting of infarcted animals that did not receive medication; 2. group LP $(n=63)$, consisting of infarcted animals that, 12 hours after surgery, received lisinopril ( $20 \mathrm{mg} / \mathrm{kg} /$ day) dissolved in drinking water, for a period of 3 months. This dosage has antiproliferating and antihypertensive effects 5 . 3 . group $C(n=10)$, consisting of the control animals, which underwent the same surgical procedure, except for the ligation of the coronary artery.

After the division of the animals into groups, they were observed and mortality was recorded.

Three months later, the animals that had survived received sodium pentobarbital (50 mg/kg) and heparin (1000 IU) by intraperitoneal via, and were ventilated with $100 \%$ oxygen with positive pressure. Their thorax was then opened, the carotid arteries were ligated, and the aorta was catheterized with a metal cannula \# 15. Retrograde myocardial perfusion was then started with the nutrient Krebs-Henseleit solution in the following compositioninmillimoles/liter(mmol/L): $115 \mathrm{NaCl} ; 5.4$ $\mathrm{KCl} ; 1.2 \mathrm{MgSO}_{4} ; 1.25 \mathrm{CaCl}_{2} ; 1.15 \mathrm{NaH}_{2} \mathrm{PO} 4 ; 25 \mathrm{NaHCO}_{3}$; and 11 glucose. Insulin $(10 \mathrm{U} / \mathrm{L})$ and mannitol $(8 \mathrm{mmol} / \mathrm{L})$ were added to assure better myocardial preservation ${ }^{6}$.

The hearts were then removed from the thoracic cavity and put into a perfusion device to be studied separately, whose specifications are size 3, type 830 (Hugo Sachs ElectronicGrunstasse, Germany), under a constant perfusion pressure of $75 \mathrm{mmHg}$. The nutrient solution was continuously oxygenated with a gaseous mixture of $95 \% \mathrm{O}_{2}$ and $5 \% \mathrm{CO}_{2}$. The partial pressure of the oxygen was kept between 500 and $600 \mathrm{mmHg}$, the $\mathrm{pH}$ between 7.3 and 7.4 , and the temperature $37^{\circ} \mathrm{C}$.

The left atrium was opened and the apex of the left ventricle was punctured with a needle to drain the ventricular cavity, avoiding accumulation of liquid in its interior. A latex-type rubber balloon attached to a rigid tube of double lumen was put inside the ventricular cavity. One of the extremities of the rigid tube was connected to a pressure transducer (Stathan $\mathrm{P}_{23} \mathrm{XL}$ ) and the other to a 1-ml syringe.

The right atrial muscle, comprising the region of the sinoatrial node, was with removed and an electrode of an artificial pacemaker was installed in the right ventricular myocardium to artificially maintain the heart rate between 180 and 200bpm.

Starling's curves were obtained with infusion of liquid inside the balloon, allowing left ventricular diastolic pressure to vary from 0 to $30 \mathrm{mmHg}$ through gradual increments of $5 \mathrm{mmHg}$. The systolic pressure corresponding to each variation in volume was recorded. In such preparations in which the heart works in isometric contractions, systolic pressure is considered a good indicator of the contractile capacity. The first derivative of pressure $(+\mathrm{dp} / \mathrm{dt})$ and the negative derivative of pressure (-dp/dt) were also recorded. These indices were used as parameters for left ventricular systolic and diastolic function, respectively.

The calibration factor of the left ventricular derivative was obtained according to the technique used by Moura Campos ${ }^{7}$.

After the functional study, the hearts were removed from the perfusion device and dried with filter paper, and the right ventricle was then dissected. The left and right ventricles (including the ventricular septum) were weighed and prepared for the morphometric analysis.

The right ventricular weight adjusted to each rat's body weight (RVW/BW) was used to estimate the degree of ventricular hypertrophy.

After being kept for 24 hours in a solution of $10 \%$ formalin, the left ventricle was put into a solution of $70 \%$ alcohol for 24 more hours as part of the process of preparation for determining the infarct size. Then a transversal cut was performed in each heart between 5 and $6 \mathrm{~mm}$ from the apex to the base. This cut reflected the mean result of the cuts in the entire ventricle ${ }^{8,9}$. Slides were assembled with the myocardial tissue, which was then stained with a solution of hematoxylin and eosin and the morphometric analysis was carried out. This analysis consisted of measurements of the epicardial and endocardial lengths of the infarcted and noninfarcted segments and calculation of the percentage of the infarcted length in regard to the total length of the left ventricle. Those infarcts $>40 \%$ of the left ventricle were considered large, and those $<40 \%$ of the left ventricle were considered small. The animals in groups NT and LP were subdivided according to their different infarct sizes.

Measurements of the concentration of hydroxyproline in the right ventricle and in the medial region of the left ventricular septum were taken according to the technique described by Switzer ${ }^{10}$.

In regard to the scientific methodology, we used survival analysis (Kaplan Meier method) to assess mortality; the differences between the curves were analyzed by the log-rank test. Individual data, the means, and the standard errors of each group were plotted to estimate cardiac hypertrophy. The differences observed were analyzed through the analysis of variance (ANOVA). An estimate of cardiac fibrosis was performed through the Kruskal-Wallis test. To test the homoscedasticity of the results obtained in each functional study, we used the Bartlett test and after this study, for comparison between the groups, we used the analysis of variance (ANOVA). The significance level employed was $5 \%$.

\section{Results}

Table I shows the number of rats in each group with small and large infarcts surviving for a period of 90 days. 
Figure 1 shows the results of the functional study performed in hearts with small infarcts. We can see that for all diastolic pressure levels, the systolic pressures are higher in group $\mathrm{C}$ as compared with those in groups LP and NT $(\mathrm{p}<0.05)$. On the other hand, the systolic pressures in group LP were statistically higher than those in group NT (A). In regard to $+\mathrm{dp} / \mathrm{dt}$ (B), we can see that, for all levels of diastolic pressure, the values of $+\mathrm{dp} / \mathrm{dt}$ are higher in group C. In addition, we can observe that for diastolic pressure levels from 0 to $20 \mathrm{mmHg}$, the values of the derivative were higher in group LP as compared with those in group NT ( $<<0.05)$. For the values of diastolic pressure of $25 \mathrm{mmHg}$ and $30 \mathrm{mmHg}$, however, the values of the derivative did not show significant differences between the groups. Similar results were obtained in regard to $-\mathrm{dp} / \mathrm{dt}(\mathrm{C})$. For large infarcts, the analysis of results shows that group $\mathrm{C}$ has statistically higher results for

\begin{tabular}{|lcc|}
\hline \multicolumn{2}{|c|}{$\begin{array}{c}\text { Table I - Groups of animals used in the morphological and } \\
\text { functional studies, } 90 \text { days after an infarction. }\end{array}$} \\
\hline Groups & S AMI (<40\% of the LV) & L AMI ( $>40 \%$ of the LV)C \\
\hline C & 10 & 10 \\
NT & 13 & 11 \\
LP & 18 & 15 \\
\hline S AMI- small acute myocardial infarct; L AMI- large acute myocardial \\
infarct; LV- left ventricle; C- control; NT- untreated; LP- lisinopril. * \\
The figures represent the number of rats in each group. \\
\hline
\end{tabular}

any variable as compared with groups LP and NT. The systolic pressure of group LP was higher as compared with that of group NT only in regard to the diastolic pressures of $0 \mathrm{mmHg}$ and $5 \mathrm{mmHg}$. For diastolic pressure levels above $10 \mathrm{mmHg}$, no significant difference occurred between the groups (fig. 2-A). In regard to $+\mathrm{dp} / \mathrm{dt}$ (B) and to $-\mathrm{dp} / \mathrm{dt}(\mathrm{C})$, the results did not show significant differences between groups LP and NT.

In regard to the estimate of cardiac hypertrophy and considering the small infarcts, a smaller RVW/BW ratio was found in the hearts of control animals as compared with those of the animals treated with lisinopril and those of the untreated animals. On the other hand, group LP had a smaller RVW/BW ratio as compared with that of group NT $(\mathrm{p}<0.05)$ (fig. 3-A). Considering the large infarcts, the RVW/ BW ratios of groups NT and LP did not show significant differences. On the other hand, group $\mathrm{C}$ showed a smaller $\mathrm{RVW} / \mathrm{BW}$ ratio as compared with that of the groups with infarction (B).

Table II shows the results of hydroxyproline concentrations. For small infarcts, we can see that group $\mathrm{C}$ had a lower hydroxyproline concentration as compared with that of the groups of infarcted animals. Groups NT and LP, however, did not show statistically significant differences. Similar results were obtained for the large infarcts.

In regard to the survival analysis, after the recovery period of 12 hours, the mortality observed in group $\mathrm{C}$ was

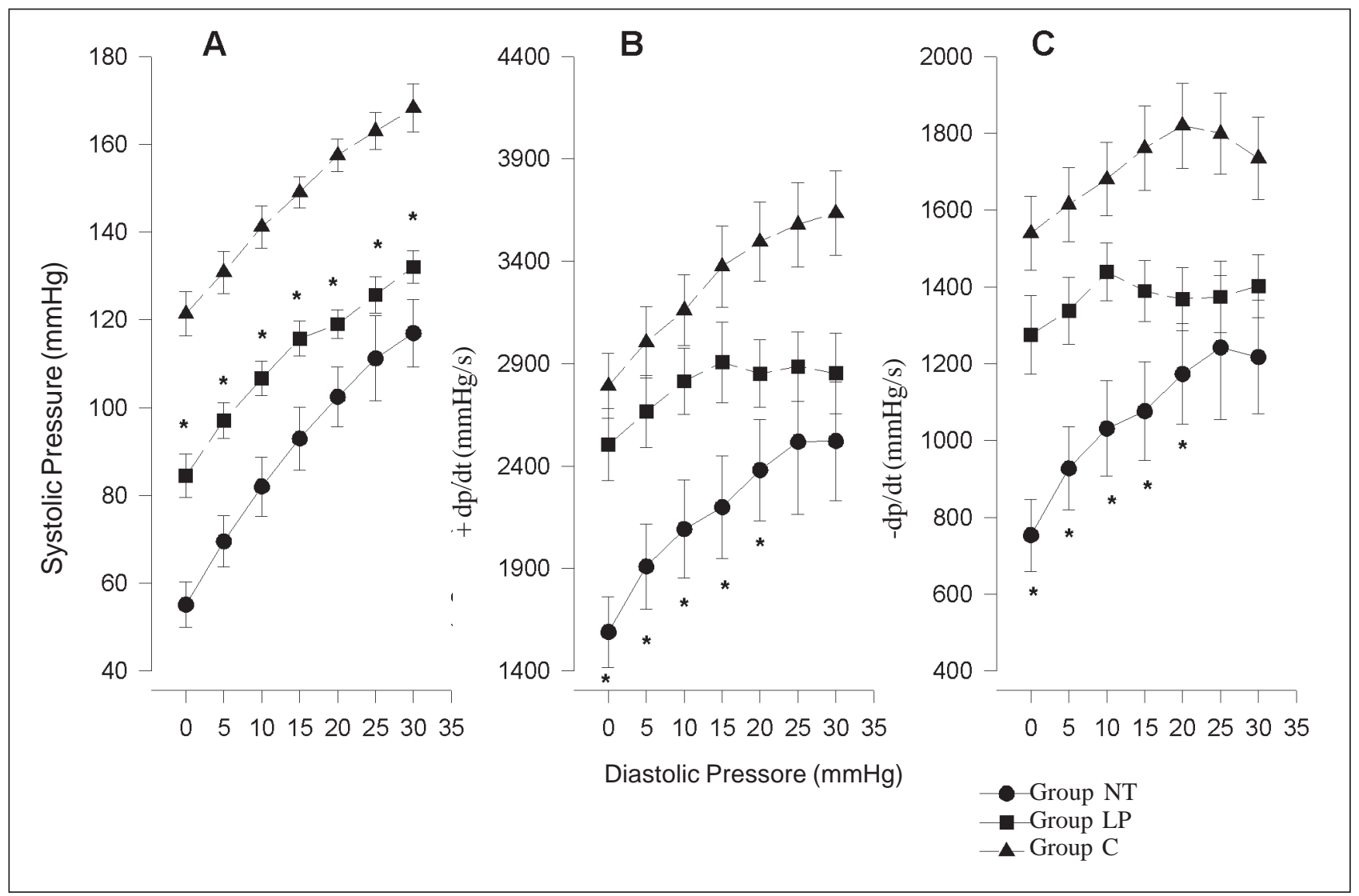

Fig. 1 - Graphic representation, in the form of mean curves \pm standard error of the functional study in small infarcts. A- systolic pressure; B- +dp/dt; C- -dp/dt; NT- untreated; LPlisinopril; C- control. *p<0.05 vs C and NT. 


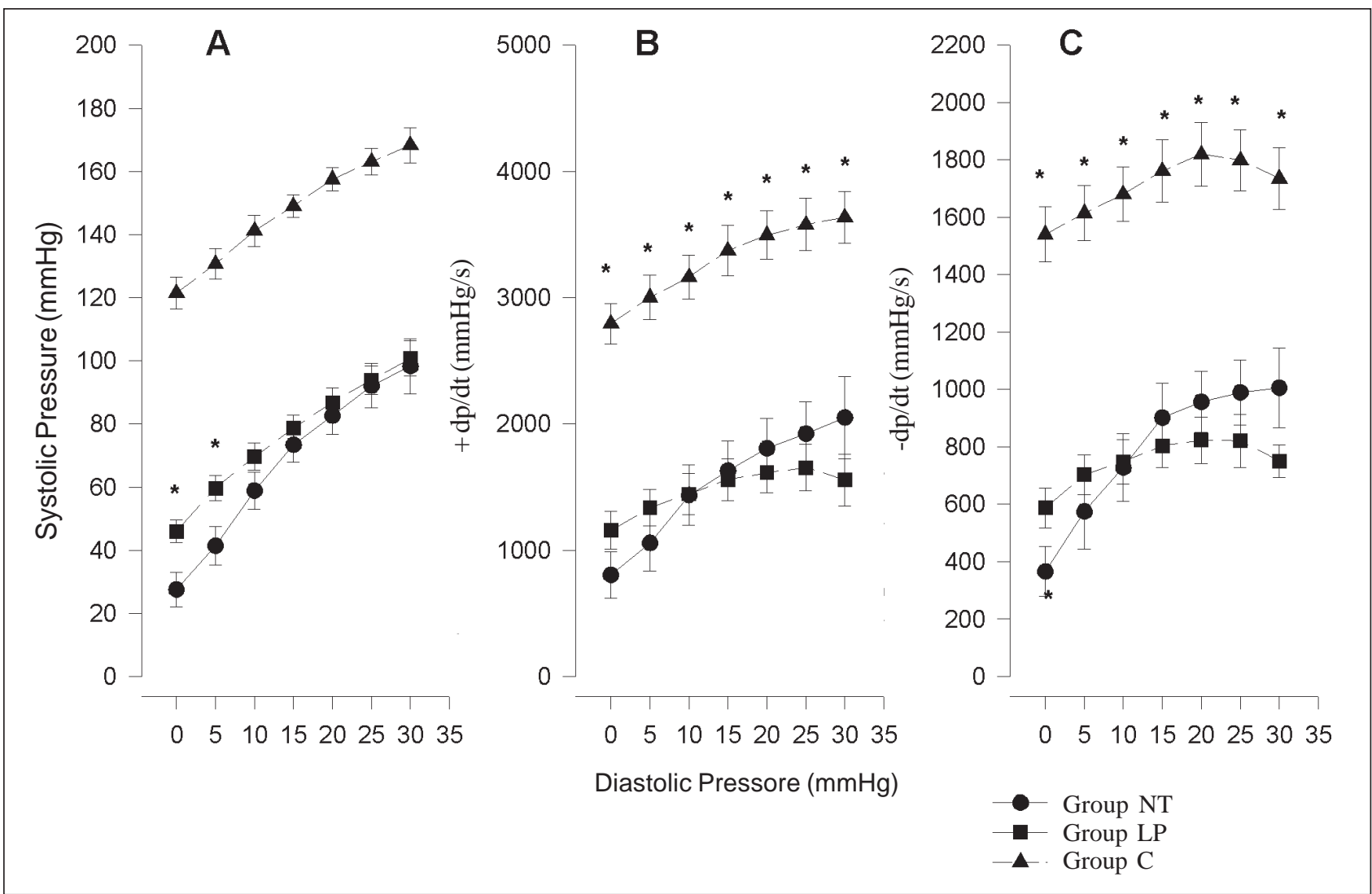

Fig. 2 - Graphic representation, in the form of mean curves \pm standard error of the functional study in large infarcts. A- systolic pressure; B- +dp/dt; C- -dp/dt; NT- untreated; LPlisinopril; C- control. *p<0.05 vs LP.

zero; in group LP it was $31.7 \%$, and in group NT it was $47 \%$. The difference between groups LP and NT did not reach statistical significance (fig. 4).

\section{Discussion}

The present study highlights the beneficial effects of the administration of lisinopril on evolutional variables of myocardial adaptations occurring after acute myocardial infarction. A critical analysis of our results indicates that the effect of lisinopril varies depending on the infarct size and the parameter analyzed.

In regard to the functional method of study, we used isometric contractions in our preparations. In such situations, the systolic pressure (SP) developed during the contractions and the $+\mathrm{dp} / \mathrm{dt}$ Have Been accepted as parameters of systolic function ${ }^{11-13}$. In the same way, -dp/dt has been used as a parameter of diastolic function ${ }^{14}$.

In regard to our results, we observed that for small infarcts the treatment with lisinopril caused an enhancement in cardiac performance, which was expressed by the parameters of systolic (SP and $+\mathrm{dp} / \mathrm{dt}$ ) and diastolic function $(-\mathrm{dp} / \mathrm{dt})$. It is worth noting that in regard to $+\mathrm{dp} / \mathrm{dt}$ and -dp/dt, group LP showed significant differences in its values, as compared with those of group NT, only up to the diastolic pressure of $20 \mathrm{mmHg}$.

For large infarcts, we did not observe differences between the two groups of infarcted animals, when the functional parameters analyzed were $+\mathrm{dp} / \mathrm{dt}$ and $-\mathrm{dp} / \mathrm{dt}$. In regard to the SP, group LP showed a greater capacity for power generation. This finding, however, was observed only with diastolic pressures of $0 \mathrm{mmHg}$ and $5 \mathrm{mmHg}$; above these levels of diastolic pressure, no difference occurred between the groups of infarcted animals. Other authors ${ }^{15,16}$ observed that infarcted rat hearts showed an improvement in functional performance compared with the control animals, when undergoing a progressive increase in diastolic pressure. Considering that the stretching of the myocardial fiber increases the degree of contractile activation, we can assume that, in our model, hearts more preserved after the ischemic injury would be less dependent on the preload for developing power. For those hearts with a higher degree of impairment, however, higher filling pressures would be necessary to reach the maximum degree of contractile activation.

Even though the ventricular weight/body weight ratio is an indirect index of cardiac hypertrophy, it is used in several experimental models to assess cellular growth. The complex sequence of events, some of which are conflicting, such as the reabsorption of necrotic myocardial tissue, the quality of the scar, and the degree of hypertrophy may interfere with the weight of the infarcted ventricle and not reflect the actual cellular growth ${ }^{17}$. Therefore, we decided to exclude this parameter from our experiment. 


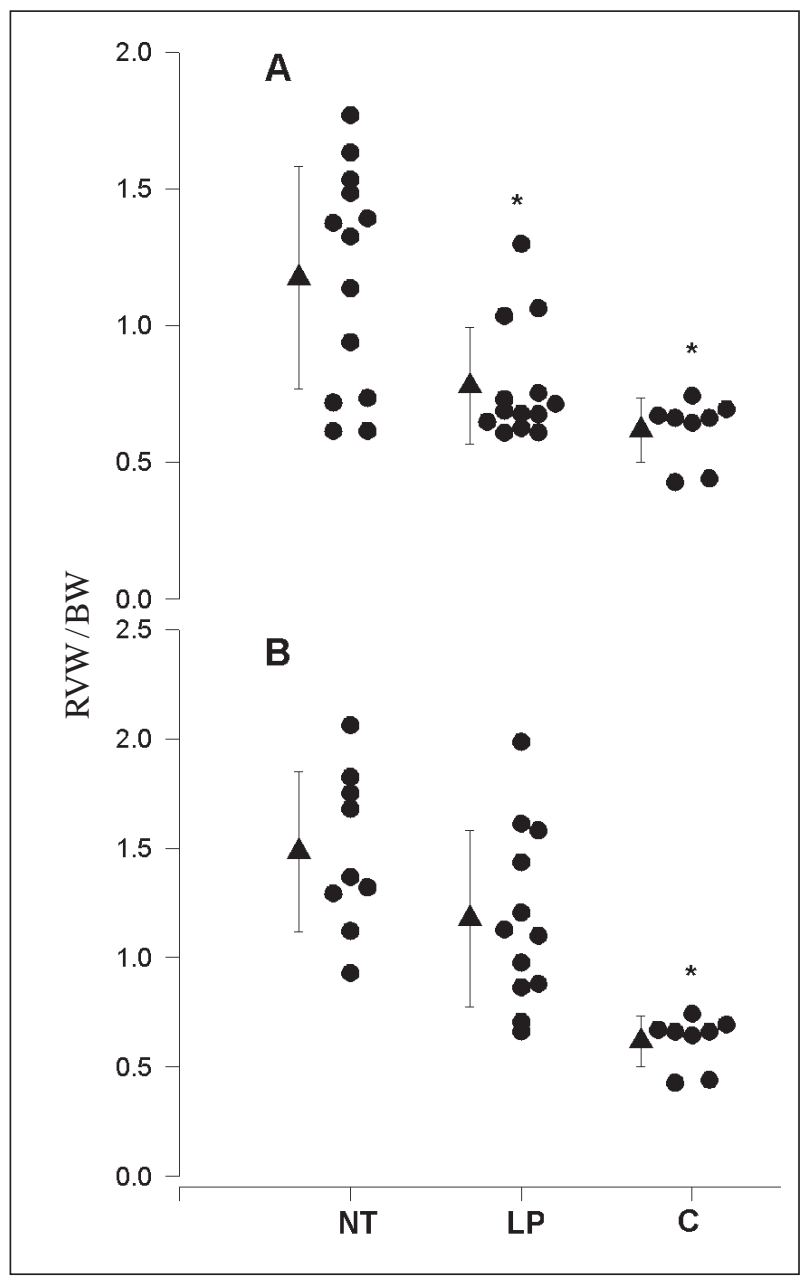

Fig. 3 - Estimate representation of cardiac hypertrophy with individual data and the means \pm standard error. A- small infarct; B- large infarct; NT- untreated; LPlisinopril; C- control. * ${ }^{*}<0.05$ vs NT.

On the other hand, a number of hemodynamic (pulmonary arterial hypertension) and neurohumoral (increase in the concentration of angiotensin II [AII] and catechola-mines, among others) changes may occur because of the impairment of the infarcted left ventricle. These events lead to an increase in left ventricular mass, characterized by growth of the myocyte, edema and collagen accumulation, which are directly related to the size of the infarcted area. According to the above, even though the increase in right ventricular mass does not reflect exclusively the hypertrophic process, the $\mathrm{RVW} / \mathrm{BW}$ ratio is accepted in the literature as a parameter of cellular growth in this model ${ }^{11,17,18}$. These findings were confirmed in a previous study ${ }^{19}$ in our laboratory, where rats undergoing occlusion of the left coronary artery showed a significant increase in the RVW/BW ratio and in the transversal diameter of the right ventricular myocytes as compared with the control animals 21 days after infarction.

In the present study, results varied according to infarct size. In large infarcts, administration of ACEIs did not alter the degree of hypertrophy. In small infarcts, however, lisinopril attenuated the adaptive hypertrophy after acute myocardial infarction.

\begin{tabular}{|l|lll|}
\hline \multicolumn{4}{|c|}{ Tabela II - Median of the values of hydroxyproline concentrations } \\
( $\mathbf{m g}$ /g of dry tissue).
\end{tabular}

In our study, the amount of collagen in the right ventricle and in the remaining tissue of the left ventricle was assessed through the concentration of hydroxyproline. Despite being an indirect quantitative method, a close correlation between the biochemical method and the amount of collagen analyzed by morphometry was found ${ }^{20,21}$. This allowed the concentration of hydroxyproline to be accepted as a parameter for the amount of collagen, in this model ${ }^{22,23}$.

In spite of the evidence that fibroblastic activity can be regulated by AII and aldosterone ${ }^{24}$, the capacity of interference of the ACEIs in the process of fibrosis is still controversial. Some authors ${ }^{23,25}$ have found that ACEIs decrease the tissue amount of collagen. Other authors ${ }^{17,22}$, however, have not shown interference of the treatment in the intensity of the postinfarction fibrosis.

In our study, we observed that infarction is accompanied by an increase in collagen concentration. On the other hand, we found no difference in the concentration of hydroxyproline between the 2 groups of infarcted animals. Our results then suggest that lisinopril does not interfere with the amount of collagen, regardless of infarct size.

Another significant finding of the present study relates to survival, as mortality in the groups did not reach statistical significance. Therefore our results do not support those results

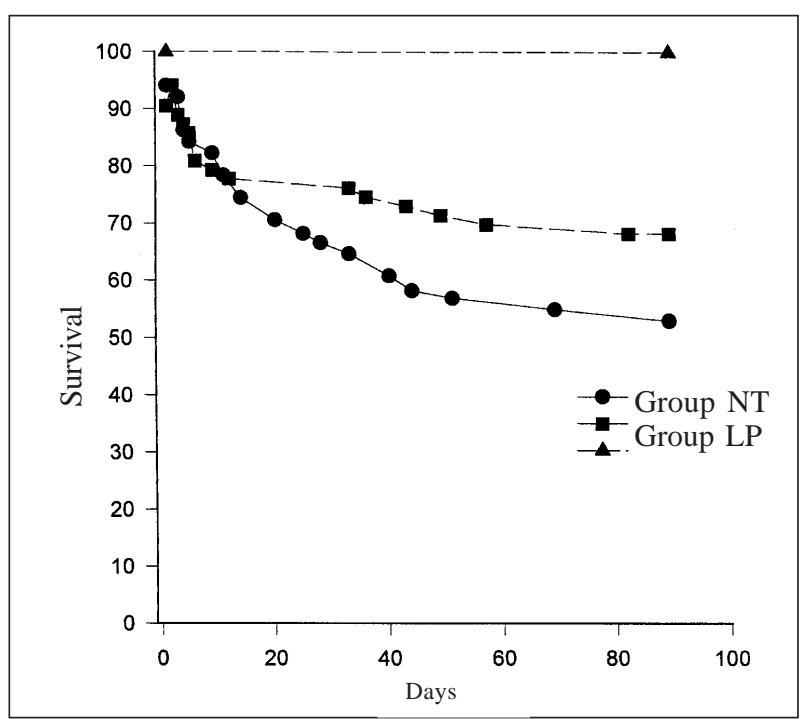

Fig. 4 - Mortality, illustrated using Kaplan-Meier curves, in the groups. NTuntreated; LP- lisinopril; C- control; $\mathrm{p}>0.05$ between NT and LP. 
of otherexperimental models, where a decrease in mortality with the use of ACEIs after acute myocardial infarction was observed 26,27 . This difference could be explained by the duration of the study as those authors observed their animals for a period of one year but our follow-up lasted only three months.

Therefore, data currently available allow the supposition that morphological and functional parameters can be precociously evaluated after an acute myocardial infarction. For analyses related to mortality, however, it would be advisable to use a longer period of observation in which differences in can become more evident.

Another hypothesis to explain the different results of our study can be based on the fact that in the 2 groups of infarcted animals, approximately half (45\%) of the deaths occurred within the first week after the infarction. Therefore, this high early mortality may have decreased the sensitivity of the statistical analysis, causing a mathematical equality. To check this possible statistical bias, we decided not to consider the animals that died within the first week after the coronary artery occlusion. The survival analysis in this new situation, during a period of 11 weeks, showed that mortality of the animals treated with lisinopril (LP) was statistically smaller than that of the untreated animals. Therefore, as a result of the already mentioned high mortality in the first days after the infarction, this experimental model may induce a statistical error.

Therefore, our results suggest that in experimental models similar to ours, studies on mortality should comprise a longer period of observation or a longer period of surgical recovery. This tactic will extend the applicability of this model in regard to the protective effect of drugs on post-acute myocardial infarction mortality.

Therefore, regarding the functional study and the estimate of cardiac hypertrophy, attenuation of the noxious effects inherent in the ventricular remodeling occurred only in those infarcts $<40 \%$ of the left ventricle.
Our results support those of other authors. Pfeffer et $\mathrm{al}^{26}$ showed that the administration of captopril to rats reduces mortality in an observational period of one year after coronary artery occlusion only in animals with infarcts that occupied from $20 \%$ to $40 \%$ of the left ventricle (moderate infarct). Animals with small $(<20 \%$ of the left ventricle) and large ( $>40 \%$ of the left ventricle) infarcts did not benefit from the treatment in regard to survival. In the same experimental model, Vollert et al ${ }^{27}$ observed that the treatment was beneficial to animals with small and moderate infarcts. The use of lisinopril, however, did not interfere with mortality in the cases with large infarcts.

Thus, currently available results allow supposing that small infarcts provide smaller physiopathological substrate to ventricular remodeling and, therefore, the effect of treatment will not have the same importance as compared with the importance of the effects obtained on moderate infarcts. In the same way, large infarcts will result in such exuberant morphological and functional changes that this phenomenon will attenuate the capacity of interference of ACEIs in the evolution of the ischemic process after an acute myocardial infarction.

Considering our results, we may conclude that the post-acute myocardial infarction use of lisinopril is accompanied by attenuation of ventricular remodeling, promoting improvement of the functional parameters and of the degree of hypertrophy. Treatment did not alter mortality or the amount of collagen. The interference capacity of lisinopril depends on infarct size and has significance only in infarcts $<40 \%$ of the left ventricle.

\section{Acknowledgments}

We thank Mrs. Valéria Maria Ricarelli de Oliveira and Mr. Mario Augusto Dallaqua for their support.

\section{References}

1. PfefferMA, BraunwaldE. Ventricular remodeling after myocardial infarction: experimental observations and clinical implications. Circulation 1990; 81: 1161-72.

2. Pfeffer MA, BraunwaldE. Ventricular enlargement following infarction is a modifiable process. Am J Cardiol 1991; 68: 127D-31D.

3. Maclean D, Fishbein MC, Maroko PR, Braunwald E. Hyalunonidase-induced reduction in myocardial infarct size. Science 1976; 194: 199-200.

4. Spadaro J, Hashimoto LM, Franco RSS, BregagnolloEA, Tucci PJF. Efeito da administração prévia de amiodarona na incidência precoce de fibrilação ventricular durante isquemia miocárdica experimental. Arq Bras Cardiol 1984; 42: 25-9.

5. Kabour A, Henegar JR, Devineri VR, Janicki JS. Prevention of angiotensin II induced myocyte necrosis and coronary vascular damage by lisinopril an losartan in the rat. Cardiovasc Res 1995; 29: 543-8.

6. ZornoffLAM,PaivaSAR, TorneroMTT,CarvalhoMSS, TucciPJF. Influênciadoacréscimo de manitol à solução nutriente no desempenho mecânico e no grau de edema miocárdico de corações isolados de ratos. Arq Bras Cardiol 1995; 64: 225-9.

7. Moura Campos $\mathrm{CF}^{\circ}$. A contração isovolumétrica do ventrículo esquerdo na estenose aórtica (Tese). Escola Paulista de Medicina - São Paulo, 1968.

8. Spadaro J, Fishbein MC, Hare C, Pfeffer MA, Maroko PR. Characterization of myocardial infarcts in the rat. Arch Pathol Lab Med 1980; 104: 179-83.

9. Oh B-H, Ono S, Rockman HR, Ross J Jr. Myocardial hypertrophy in the ischemic zone induced by exercise in rats after coronary reperfusion. Circulation 1993; 87: 598-607.

10. Switzer BR. Determination of hydroxiproline in tissue. J Nutr Biochem 1991; 2:229-31.

11. Pfeffer MA, Pfeffer JM, Fishbein MC, et al. Myocardial infarct size and ventricular function in rats. Circ Res 1979; 503-12.

12. Raya TE, Gay RG, Lancaster L, Aguirre M, Moffett C, Goldman S. Serial changes in left ventricular relaxation and chamber stiffness after large myocardial infarction in rats. Circulation 1988; 77: 1424-31.

13. Litwin SE, Raya TE, Anderson PG, Litwin CM, Bressler R, Goldman S. Induction of myocardial hypertrophy after coronary ligation in rats decreases ventricular dilatation and improves systolic function. Circulation 1991c; 84: 1819-27.

14. Zile MR, Conrad CH, Gaasch WH, Robinson HG, Bing OHL. Preload does not effect relaxation rate in normal, hypoxic, or hypertrophic myocardium. Am J Physiol 1990; 258: H191-9.

15. Mill JG, Stefanon I, Leite CM, Vassalo DV. Heterometric regulation and calcium sensitivity of the infarcted rat heart. Braz J Med Biol Res 1991; 24: 429-36.

16. Stefanon I, Martins MA, Vassalo DV, Mill JG. Analysis of right and left ventricular performance of the heart with chronic myocardial infarction. Braz J Med Biol Res 1994; 27: 2667-79.

17. Litwin SE, Raya TE, Warner AL, Litwin CM, Goldman S. Effects of captopril on 
contractility after myocardial infarction: experimental observations. Am J Cardiol 1991b; 68: 26D-34D.

18. Anversa P, Beghi C, MacDonald SL, Levicky V, Kikkawa Y, Olivetti G. Morphometry of right ventricular hypertrophy induced by myocardial infarction in the rat. Am J Pathol 1984; 116: 504-13.

19. Spadaro J, Cicogna AC, Tucci PJF, Cury PR, Montenegro MR. Morphometric evaluation of the time course of right ventricular hypertrophy after left coronary artery ligation in rats. Braz J Med Biol Res 1989; 22: 517-22.

20. Weber KT, Janicki JS, Shroff SG, Pick R, Chen RM, Bashey RI. Collagen remodeling of the pressure-overloaded, hypertrophied nonhuman primate myocardium. Circ Res 1988; 62: 757-65.

21. Nicoletti A, Mendes D, Hinglais N, et al. Left ventricular fibrosis in renovascular hypertensive rats. Effect of losartan and spironolactone. Hypertension 1995; 26: 101-11.

22. Litwin SE, Litwin CM, Raya TE, Warner AL, Goldman S. Contractility and stiffnes of noninfarcted myocardium after coronary ligation in rats. Effects of chronic angiotensin-converting enzyme inhibition. Circulation 1991a; 83: 1018-37.

23. Mill JG, Milanez MC, Busatto VC, Moraes AC, Gomes MG. Ativação da enzima conversora de angiotensina no coração após infarto do miocárdio e suas repercussões no remodelamento ventricular. Arq Bras Cardiol 1997; 69: 101-10.

24. Brilla CG, Zhou G, Matsubara L, Weber KT. Collagen metabolism in cultured adult rat cardiac fibroblasts: response to angiotensin II and aldosterone. J Mo Cell Cardiol 1994; 26: 809-20.

25. Michel J-B, Nicolletti A, Arnal JF. Left ventricular remodeling following experimental myocardial infarction. Eur Heart J 1995; 16(suppl I): 49-57.

26. Pfeffer MA, Pfeffer JM, Steimberg BS, Finn P. Survival after an experimental myocardial infarction: beneficial effects of long-term therapy with captopril. Circulation 1985b; 72: 406-12.

27. Wollert KC, Studer R, Bulow B, Drexler H. Survival after myocardial infarction in the rat. Role of tissue angiotensin-converting enzyme inhibition. Circulation 1994; 90: 2457-67. 